Logos Universality Mentality Education Novelty, Section: Philosophy and Humanistic Sciences

ISSN: 2284-5976 (print), ISSN: 2284-5976 (electronic)

Covered in: CEEOL, Index Copernicus, Ideas RePEc, EconPapers, Socionet

\title{
AUTHOR IDENTITY IN SCIENTIFIC TEXTS ON ECONOMICS
}

\section{Teodora GHIVIRIGA}

Logos Universality Mentality Education Novelty, Section:

Philosophy and Humanistic Sciences, III (1), 99-113

The online version of this article can be found at:

http://lumenjournals.com/philosophy-and-humanisticsciences/

Published by:

Lumen Publishing House

On behalf of:

Lumen Research Center in Social and Humanistic Sciences 


\title{
Author Identity in Scientific Texts on Economics
}

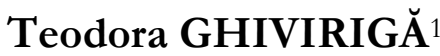

\begin{abstract}
Self reference has been widely studied either in comparable corpora or in learners corpora, especially in English, some other major languages as well (Spanish, French), however, texts in Romanian have not been subject to such investigations. The present paper aims at identifying and discussing the manner in which Romanian authors of texts on Economics present themselves to their peers. In the paper the concept of author identity is explored in its linguistic expression in Romanian in the form of first person personal pronouns (direct and oblique cases) and possessives (singular and plural) and verbs in the $1^{\text {st }}$ person singular and plural. Quantitative data are provided on the roles of the first person forms in the texts, according to the typology in Flottum et al. (2006) also taking into account the specific ambivalent position of the PhD student as student and researcher. The possible influences of cultural patterns (French) and domain specific practices are also considered in the analysis and interpretation of data. Prevalent use of the author as researcher is found, with reduced presence of the author as writer, suggesting the possibility to integrate Romania as a reader responsible culture. Overall, the authors prefer to express themselves by means of $1^{\text {st }}$ person plural in both pronominal and verbal forms.
\end{abstract}

\section{Keywords:}

Academic writing, author identity, self-reference, Economics, corpus.

${ }^{1}$ PhD, Alexandru Ioan Cuza University of Iaşi, Romania, teoghivi@yahoo.com

Ghiviriga, T. (2015). Author Identity in Scientific Texts on Economics. Logos Universality Mentality Education Novelty, Section: Philosophy and Humanistic Sciences, III (1), 99-113 


\section{Introduction}

Science cannot be created, transmitted and even conceived of outside the system of language, mainly in its written form: although there may be alternative ways in which science is discussed, most of it is still disseminated nowadays via the written medium. This has allowed and, to a certain extent, imposed pre-established forms that deploy certain patterns and result from certain practices that linguists and rhetoricians have termed genres. They range from grant proposals, to dissertations to abstracts etc., to the research articles (RA) which is perhaps the best known, most widely used and most thoroughly researched. These types - or genres - have a pre-established structure (the RA, for example, as discussed first by Swales, 1990, and then by many others, has the basic IMRD model) and any scientific work that seeks official recognition will observe this form.

However, on studying the various genres, linguists have remarked on slight alterations from this generally accepted pattern and have tried to identify the source of such differences. They come from the fact that scientific texts are not - as one might expect - the universal, impersonal product of an impersonal, perfectly objective scientist, but rather they are mixtures of various factors that combine flavours to create unique combinations. The elements that have been identified to play a role are: the genre itself, discipline (Maths vs History, for example, as each domain carries its own epistemological groundings and premises), the language in which it is written (and whether it is the writers' native language), along with the culture associated with it, the status and level of experience of the scientists (from novice - BA and MA students to well established members of the scientific community), and, of course, the writers' individual background, who carries along all manner of idiosyncratic features that may become apparent in the text. At the intersection of all these factors lies the profile of the writer.

\section{Review of literature}

The study of differences in textual realization resulting from various rhetorical choices influenced by various cultures and linguistic backgrounds have been termed along the time contrastive rhetoric (Kaplan, 1966), intercultural rhetoric (Connor, 1996, 2004) refined to Contrastive Interlanguage Analysis (CIA), which compares non-native speakers and native speaker's language production in similar situations 
(Granger 1998), or the doubly contrastive approach (Dahl, 2004). The most thoroughly studied genre - most likely because the most visible, since scholarly reputation and institutional evaluation depend on it - is the research article, but other genres have been investigated: abstracts, grant proposals, MA papers. Most work focuses on the contrastive approach of texts written by native English authors and L2 authors in English of various origins: French, Spanish, German, Finnish, Swedish, Polish, Bulgarian and Russian in Europe, and many of Asian origin. The status and degree of expertise of the writers has also been considered, with contrastive studies of texts produced by novice vs expert writers. Much research was directed towards establishing whether the domain or discipline bears any consequence on the author's rhetorical choices. More complex studies such as the KIAP (2006) project were directed at establishing the manner in which several factors (language, culture, discipline) interact. The size of the corpora varies from a few articles to hundreds, from tens of thousands of words to some of over a million (Hyland, 2001, Flottum et al., 2006) and, given the advances in text processing software, the size of new corpora is increasing as we speak.

The results are not only interesting, but also contradictory in some cases. With respect to disciplinary variation, for instance, articles in medicine appear to be the most formalized and uniform irrespective of the linguistic and cultural background of the writer; in natural sciences there is a general tendency to minimize authorial presence, while articles in linguistics, for instance, show greater variability in this respect; on the other hand, Swales and Feak (2004, 284-285) found that physicists and chemists are "perhaps surprisingly" more likely to adopt a personal stance, through the use of the pronoun "we", than specialists within the social sciences. In terms of presence in the text, novice writers have been shown to be much shyer and less willing to risk overt presence and opinion in the text by using personal pronouns (in English, where the presence of the pronoun in subject position is obligatory) than experienced researchers, whose textual "voice" is more overtly deployed in presenting opinion and results.

The author's linguistic and cultural background is a complex factor that influences the choice, frequency and distribution of rhetorical instruments. French writers, for instance, completely avoid the use of the 1st person singular and heavily rely on impersonal constructions using on, while Norwegian writers are more similar in this respect to 
English writers, who beside using impersonal constructions (passive mainly) make constant use of 1 st person both singular and plural, in varying proportion and for various purposes. The Finnish writers' text has been described as using much less metatext $(22.6 \%)$ than that of the native-English writers' (54.2\%), who generally shows a higher awareness of the text (Mauranen, 1993); a possible explanation lies in the AngloAmerican and Norwegian writers' preferences for rhetorical strategies which seem to reflect very different notions of politeness. Among Romance languages writers, the French use much less metatext than do both English and Norwegian; also a tendency of native-English speakers to place topic sentences at the beginning of an article has been identified, whereas writers of Hispanic origin (and also Finnish and German as Mauranen (1993) and Clyne (1987) show in their studies) tend to include them later in the text.

The purpose of the present paper is to investigate and outline the profile of the Romanian writer of scientific texts (the specific domain being Economics) with respect to self reference (in pronominal, possessive and verbal forms). The use of the author's native language would ensure that they feel comfortable enough to make a choice of words that would be representative of their identity, both cultural and disciplinary. The genre selected for this investigation is the $\mathrm{PhD}$ dissertation, as this is at present the most readily available and compact scientific text of Economics in Romanian, while RA are increasingly written and published in widely circulated languages, English mainly, and therefore more difficult to find in order to compile a corpus with. The corpus consists of $13 \mathrm{PhD}$ dissertations in theoretical Economics defended between 2009 and 2014, written in Romanian, which is still the compulsory language for defending doctoral theses. The corpus is a little above 1 million words (1,004,478 tokens of running text), numbers and other symbols excluded, which means 39422 types (different words and forms of words). The texts have been prepared for research and the initial parts (contents) and final parts (Annexes, References) have been removed, along with tables, graphs and formulae, where they existed (although one criterion in selecting the papers was that they were mainly theoretical with comparatively few such elements). The searches were run with specialized software, the concordancer Antconc, which can provide basic statistics (number of tokens/items), concordances, as well as plotting (the visualized distribution of an item in the text). Since 
Romanian has rich inflectional forms and the corpus was raw, the search was done using wildcards and several elements have been marked manually.

The first step was deciding on variables that can most aptly provide the relevant information. Each of us is constantly influenced by a multitude of discourses situated in the groups we are part of (Hyland, 2002, 1094). The linguistic choices may reveal differences between the education systems, the intellectual styles, and the attitudes to knowledge and content (Valero Garcez, 1996, 280). This socially defined rhetorical identity is accomplished through a range of rhetorical and interactive features, but most visibly in the use of first person pronouns and possessive determiners (Hyland, 2002). Authors may refer to themselves through various means such as lexical expressions ("the author", "this study"), citation of previous studies, the passive voice ("this test was conducted"), but the most frequent means is currently via personal pronouns (Fløttum et al., 2006). The use of this class has also been seen as a manner of displaying power and authority (Hyland, 2002).

The linguistic realization of the authorial person in texts has been approached from various perspectives. Hermans proposes that the authorial "I" is not unitary but divided, decentered, dispersed: "There is no single ' $\mathrm{I}$ ' but several, relatively independent ' $\mathrm{I}$ ' positions that complement and contradict each other in dialogical relationships." (in Reed \& Duke, 2005, 507). Several taxonomies have been proposed for the classification of writer pronouns (Tarone, et al. 1998; Vassileva, 1998; Tang and John, 1999; Hyland, 2001, 2002; Harwood, 2005). Neisser (in Reed and Duke, 2005) proposes that there are five kinds of selves, all of which contribute to overall self-knowledge: ecological self, interpersonal self, extended self, private self, conceptual self. Clark and Ivanic (1997) distinguished three aspects of identity that writers bring to any act of writing: the autobiographical self, influenced by their personal life-history, opinions and beliefs about the ideas on the text; the discoursal self, used to claim membership to a group with whom they share practices and discourses; the authorial self, which manifests itself as authoritativeness in relation to the contents of the text. In Tang \& John (1999), the roles are distributed along a continuum starting with no authorial presence and moving on to 1 . I as representative; 2 . I as the guide; 3. I as the architect; 4. I as the recounter of the research processes; 5 . I as the opinion holder and 6. I as the originator. More 
elaborate taxonomies have been produced starting from these: Mur Duenas (2006, 151 - 153) finds that personal pronouns serve eight different rhetorical functions: Explaining a procedure; Making a claim or statement, elaborating an argument; Stating a hypothesis, an expectation or a wish; Stating a goal or purpose; Showing results or findings; Assessing the limitations of their research; Assessing the limitations of their research; Outlining the steps followed in the RA. Cârciu (2009) also proposes an adapted version of Tang and John (1999) with "we" roles distribution depending on whether they belong to the real world or the world of discourse.

Since these taxonomies were created with English in mind, and since researchers have remarked on the fact that due to the rather large number of types, they tend to overlap and can therefore be cumbersome when applied, in the present paper the decision was made to use the taxonomy suggested in the KIAP $(2006,83)$ project, consisting of four roles. This classification was initially devised to accommodate three languages of different typology, both Germanic (English and Norwegian) and Romance (French) and is also more manageable: "In our view a restricted number of roles may contribute to a more general rhetorical characterisation of author presence in research articles and enable a comparison between different disciplines." (ibid.) Another advantage of this model is that it allows for mixed roles, which reflected the reality in the Romanian corpus, and for a further residual group, where cases which do not fall into any of the classes or which are difficult to decide on were grouped in. The four basic roles are: the author as writer (AW), as researcher (AR), as arguer (AA) and as evaluator (AE). A class was added marked as QQ, where 1st person forms are included in quotes and therefore do not belong to the writers themselves: though not very large, it is a segment that needed separate tallying as it could not be included in any of the above mentioned groups.

Moreover, since in Romanian the person/number information is incorporated in the form of the verb, with the pronoun absent/implied, in most cases - and this is obvious if we compare the values for verbs and for pronouns in the 1 st person plural - the person was manifest in the verb form, so it would be far more salient to consider verbs and not pronominal forms only. The KIAP (Fløttum, 2006, 83 - 84) methodology allows for this, as in their project the verb meaning is 
considered as the first criterion the groups of verbs are classified by: a. discourse verbs (e.g. summarise, (re)turn to): typically manifested in the writer role; b. research verbs (e.g. analyse): typically manifested in the researcher role; c. position verbs (e.g. claim): typically manifested in the arguer role; d. evaluation and emotion verbs and verb constructions (e.g. be sceptical about, feel: typically manifested in the evaluator role. Here some examples from the corpus are provided of the basic four roles: a. AA considerăm necesar a verifica o posibilă corelație [10] (we consider it necessary to check a particular correlation...); b. AR În plus, am căutat să vedem cum au evoluat fiecare dintre acestea [3] (moreover, we have sought to see how each of these have evolved...); c. AE cheltuieli, ci doar cele pe care le considerăm mai relevante (numai pentru cazare, (expenditures, but only those that we consider to be more important (only for accomodation)...); d. AW mondial. In cadrul capitolului am încercat să punctăm avantajele şi dezavantajele procesului de [2] (global. Within the present chapter we have tried to point out the advantages and disadvantages of the process which...) (author's translation).

\section{Discussion}

Generally scientific prose is written - and hence has been described - as impersonal, detached, emanating from a self-effacing author who steps back in order to allow for the facts to speak for themselves (especially in the hard sciences) and has been referred to as "author-evacuated" prose (Geertz, 1988, in Harwood, 2005, 1208). Various instruments are used (in English and in other languages as well) to achieve this effect of self-effacement, this withdrawal of the author from the text: passive structures, usually with no agent mentioned, the use of pronominal forms such as on in French, one in English or man in German, passive reflexive structures in Romanian etc.

As can be seen in tables 1 and 2, the presence of the author as expressed by pronouns and related forms (emphatic, determiners) is clearly in favour of the 1 st person plural; the expressed 1 st person singular barely exists: it appears in a few isolated examples and in several quotes. In the vast majority of the cases, the 1 st person plural was chosen by the Romanian authors. What is interesting to note, though, is the distribution of these numbers across the forms that provide information on the combination person/number: the form favoured by Romanian scientists is, in this order, the oblique, the possessives and 
lastly the nominative form in subject position. In the specialised literature, the last one is considered stronger than the oblique forms (Dative, Accusative), which in turn are felt as stronger than the possessive determiners (again this interpretation is for English, but I think it can be applied to Romanian as well). When the pronoun in the subject position is used, the author takes the full responsibility for his claims; what can be inferred from the data in the corpus is that the Romanian authors have a strong preference for the oblique case (which may also be accounted for in terms of the redundancy of dative accusative forms in Romanian). This has been associated with texts by novice writers, who feel insecure about the claims they make; if corroborated with other data, this may indicate that the $\mathrm{PhD}$ students who produced the texts may display a certain amount of insecurity when asserting themselves in writing. In certain rhetorical situations, self references can strengthen an argument, which is what the Romanian authors seem to choose to avoid. On the other hand, a too overt authorial presence has also been interpreted as patronising (Mauranen, 1993) and even face threatening: PhD students who have to defend their thesis in front of a committee in order to be awarded the degree may not want to take the risk of appearing patronizing or make claims that might be interpreted as having a face threat value.

Given the inflected nature of Romanian, the verb forms were the main element that I relied on in my approach. The present tense forms were counted, which should, however, prove relevant since LSP rhetoric describes the present as the most frequently used and the most salient form/tense in the case of scientific and technical prose. A cursory glance at the future forms, however, which are more easily treated due to the person/number marked auxiliary voi/vom once again reveals the preference for the 1 st person plural to the detriment of the singular (voi 21 vs auxiliary vom 278). Also a comparison of the figures for the past form of the verbs as apparent from the counts for the past tense (Perfect Compus) auxiliary am 1st person singular and plural (839 occurrences) vs the total number of 1 st person plural Present (3416 occurrences) seems to validate this position.

Since the aim of the present paper is to analyse the degree of self-representation, as expressed by self-mentions, and also the purposes linguistic self mention serves, in the process of establishing the identity of the author I attributed each verb in the present tense in the 1 st 
person plural one (in a few cases two) of the roles in the KIAP model selected. From the figure (Figure 1.) it becomes apparent that most authorial presence is established by means of verbs in the present tense in the role of author as researcher $(55 \%$ of the total count of verbs in the 1 st person plural and $66 \%$ of the total count of verbs in the exclusive 1 st person plural), with some attention paid to the role of author as arguer $(16 \%$ of the total count of verbs in the 1 st person plural) and very little weight to the roles of author as evaluator $(2 \%)$ and author as writer (4\%). The fact that through the rhetorical instruments used, the writers attempt to establish themselves primarily as researchers is no surprise, since this is the main purpose of the $\mathrm{PhD}$ thesis. What is interesting to the point of disconcerting is the very low profile of the other two roles: that of evaluator and of writer; this is in sharp contrast with the figures in Fløttum $(2006,91)$, where the role of the author as writer rises to a quarter of all cases $(26 \%)$, with less than a half for the writer as researcher (46\%); a comparison is, not, however, entirely relevant here since the figures provided in the above mentioned study refer only to $1^{\text {st }}$ person singular forms, which are virtually absent from the Romanian corpus. The disparity can be partly accounted for in terms of language and genre. On the one hand, the writers may feel that they are not yet in a position to easily take the role of evaluator in a text where much of the discourse consists of direct or indirect reference to well established, nay, sacred figures of the domain such as Adam Smith or Keynes, as well as to valued members of the community, including the $\mathrm{PhD}$ supervisor, so their shyness is understandable to a degree.

On the other hand, however, the very diminutive presence of the author as writer lends itself to an interesting interpretation. This role gives the measure of the author's awareness as the producer and organiser of the text: it implies that the author is ready to take the responsibility of the communication with the reader. The author guides the reader through both the text as a product and its scientific content by referring to parts of the text (in this chapter), to the sequence of moves (as shown previously), to the mathematic and/or graphic apparatus (as shown in Table 3). A reduced amount of metatext in general, and of the author in this role, has been interpreted as a position which assumes a great deal of shared knowledge between the communicants (Mauranen, 1993, 18), which is partly so in the particular case of the $\mathrm{PhD}$ thesis target readers. The same phenomenon, however, has also been interpreted as 
the sign of the author belonging to what has been termed as reader responsible cultures as opposed to writer responsible cultures, of which the best example is the Anglo-Saxon culture: Anglo-Americans appear to show greater awareness of the text as text, to be more oriented towards the reader. Germans, French, Finns are, on the other hand, examples of the reader responsible cultures: the author focuses on the propositional content of the text, or the text-external reality that they are dealing with (Mauranen, 1993, 16), and relies on a more active reader to contribute to the creation of meaning, the drawing of conclusions etc. This is, to a certain extent, supported by direct reading experience: many Romanians have experienced being more or less forced into the reader responsible culture, when they had to struggle sometimes with rather obscure terminologies, lack of adequate fluid textual organization or of discourse markers.

Interestingly, greater prominence is given comparatively to the inclusive pronominal forms of generalizing value (marked IG in the corpus), whose occurrences outnumber the previous two roles. In one of the theses this generalization is imposed by the nature of the topic, which is de-growth, as a picture is given of the consumerism ridden world we live in and examples are provided of what "we", inhabitants of Planet Earth, do; the rest, however, is an interesting continuation of the secondary education discourse from middle and high school as expressed in formulaic language of the type "în aceasta poezie noi vedem" (in this poem we can see that...), "prin acest experiment noi arătăm că..." (with this experiment we can prove that...). In this particular type of discourse the use of inclusive "we" is justifiably meant to include the young audience and make it part of the discovery process; however, in academic/scientific discourse, it may result in the readers feeling as if the author's own view is imposed on them through overgeneralization in cases where an impersonal or a more subtly nuanced wording is required. It may also be construed as the reflex of a communistic - as opposed to a more individualistic - culture that Romania may be said to belong to.

\section{Conclusions}

The results show a significant preference for the 1st person plural (pronominal and verbal forms) to the detriment of the 1st person singular, which is consistently avoided and only occurs in quotations 
where other economists' words are repeated. The French cultural model is the closest in this respect (Hartwell \& Jacques, 2014, 5) and, given the history of cultural influence from this direction, this could be a possible explanation. One other set of values resulting from the present research indicate the Romanian writers' significant preference for oblique forms over those in subject position, with the possessive determiners as the second choice.

Beside the number of inclusive we (some triggered by the special nature of the topic, some resulting from formulas typical of pedagogical discourse, no longer necessary or advisable in this genre) and a small ratio of 1 st person singular and plural forms included in quotations, most of the 1 st person verbal forms are associated to the role of the author as researcher, with a second position for the role of the author as arguer and with small values for the roles of the author as evaluator and writer. While a reduced proportion of forms where the author is manifest as evaluator are consistent with similar studies (Fløttum et al., $2006,91)$, the counts for the role of the author as writer are surprisingly low and seem to indicate reduced awareness on the part of the Romanian economists of the complex process of text production or desire to appear in the text as guides to the reader. From this study and this indicator - alone, Romania appears as a representative of the reader responsible culture, paired again with the French (or Finnish, or Polish, or German, see Fløttum et al., 2006, Duszak, 1994, Mauranen, 1993) and in contrast with the Anglo-Saxon. On the other hand, this preference may be the result of lack of extensive and thorough writing instructions and of appropriate models in the process of producing scientific discourse or of lack of knowledge of generally accepted norms.

Table 1. $1^{\text {st }}$ person pronouns (singular and plural)

\begin{tabular}{|l|l|l|}
\hline Form & $\begin{array}{l}\text { Singular (normalized per } \\
10,000 \text { words) }\end{array}$ & $\begin{array}{l}\text { Plural (normalized per } \\
10,000 \text { words) }\end{array}$ \\
\hline Subject /nominative & 0 & 0.866 \\
\hline Oblique & 0.1 & 11.505 \\
\hline Determiners & 0 & 0.059 \\
\hline Emphatic/reflexive & 0 & 0.089 \\
\hline $\begin{array}{l}\text { Total number of } \\
\text { present } 1 \text { st person } \\
\text { occurrences }\end{array}$ & 0.21 & 18.31 \\
\hline
\end{tabular}


Table 2. Verb forms.

\begin{tabular}{|l|l|}
\hline Form & $\begin{array}{l}\text { Normalized value } \\
/ 10,000 \text { words }\end{array}$ \\
\hline Viitor / future 1 ${ }^{\text {st }}$ person sg (auxiliary voi) & 0.2091 \\
\hline Viitor / future 1 ${ }^{\text {st }}$ person pl (auxiliary vom) & 4.76 \\
\hline Perf. Simplu/Past tense (auxiliary am) sg + pl & 8.357 \\
\hline Prezent/Present tense conjugation 1 & 13.49 \\
\hline Prezent/Present tense conjugation $2 \& 3$ & 15.26 \\
\hline Prezent/Present tense conjugation 4 & 4.95 \\
\hline
\end{tabular}

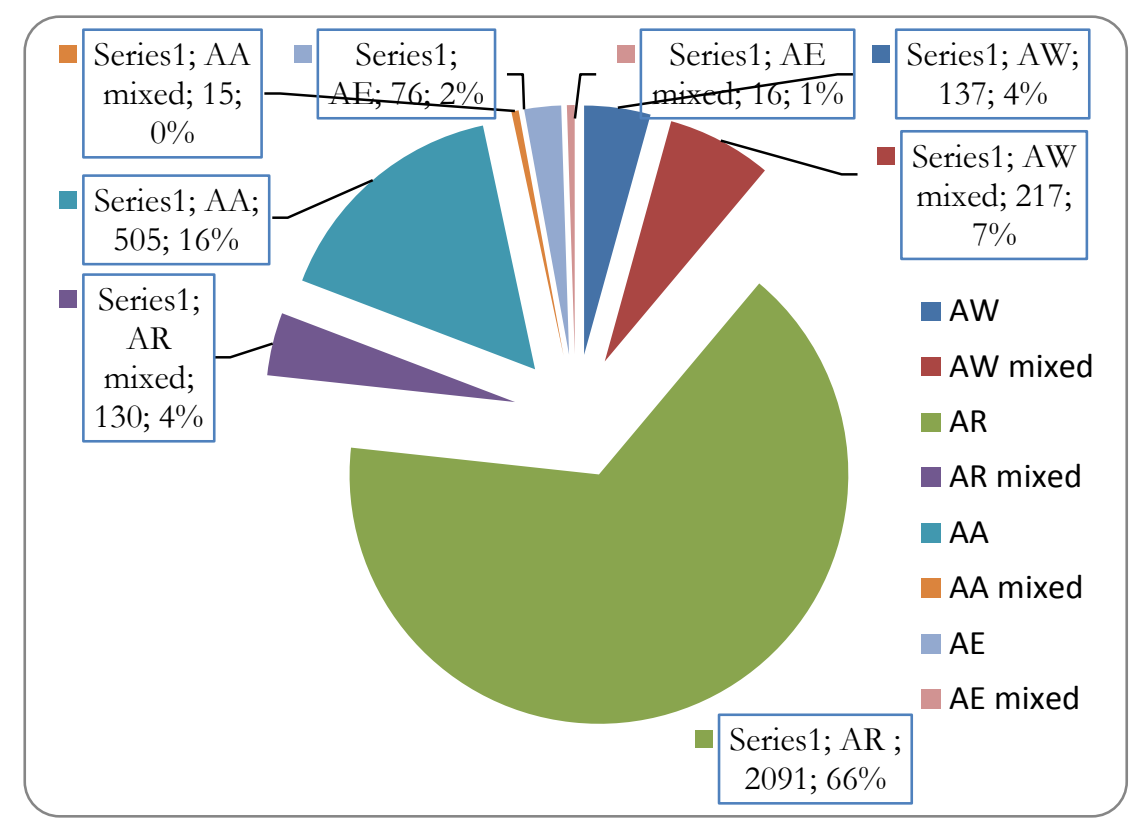

Fig. 1 - Values for the four author roles

\section{References}

Anthony, L. 2014. AntConc (Version 3.4.3) [Computer Software]. Tokyo, Japan: Waseda University. Available from http://www.laurenceanthony.net/

Cârciu, Oana Maria (2009). An intercultural study of first-person plural references in biomedical writing. Iberica 18, 71-92.

Ghiviriga, T. (2015). Author Identity in Scientific Texts on Economics. Logos Universality Mentality Education Novelty, Section: Philosophy and Humanistic Sciences, III (1), 99-113 
Clark, R., Ivanic, Roz (1997). The Politics of Writing, London: Routledge.

Clyne, Michael (1991). The sociocultural dimension: The dilemma of the German-speaking scholar Subject-oriented Texts. In Hartmut Schröder (ed.), Language for Special Purposes and Text Theory, Berlin, New York: de Gruyter.

Clyne, Michael (1987). Cultural Differences in the organization of academic discourse. Journal of Pragmatics, vol 11, 211 - 247.

Connor, Ulla, et al. (2008). Contrastive Rhetoric. Reaching to intercultural rhetoric. Amsterdam / Philadelphia: John Benjamins.

Connor, Ulla (1996). Contrastive Rhetoric. Cross Cultural Aspects of Second Language Writing, Cambridge University Press.

Dahl, Trine (2004). Textual metadiscourse in research articles: a marker of national culture or of academic discipline? Journal of Pragmatics 36, 1807-1825.

Duszak, Anna (1994). Academic discourse and intellectual styles. Journal of Pragmatics 21 (3), 291-313.

Fløttum, Kjersti, Trine Dahl and Torodd Kinn. (2006). Academic Voices: Across languages and disciplines, John Benjamins Publishing Company.

Granger, Sylviane \& Paul Rayson (1998). "Automatic profiling of learner texts”, in Granger, Sylviane (ed.), Learner English on Computer. (pp. 119-131) London \& New York: Longman.

Hartwell Laura M., Marie-Paule Jacques (2014). Authorial Presence in French and English: "Pronoun + Verb" Patterns in Biology and Medicine Research Articles. Discours, Revue de linguistique, psycholinguistique et informatique, 15, 1 - 21 .

Harwood, Nigel (2005). 'Nowhere has anyone attempted . . . In this article I aim to do just that' A corpus-based study of selfpromotional I and we in academic writing across four disciplines. Journal of Pragmatics 37, 1207-1231.

Hyland, Ken (2002). Authority and invisibility: authorial identity in academic writing. Journal of Pragmatics 34, 1091-1112.

Hyland, Ken (2001). Humble servants of the discipline? Self mention in research articles, in English for Special Purposes 20, 207 - 226.

Kaplan, Robert B. (1966). Cultural Thought Patterns in Inter-cultural Education, reprinted from Language and Learning 16 (1-2), 11 25. 
Mauranen, Anna, (1993). Contrastive ESP Rhetoric: Metatext in Finnish-English Economics Texts. English for Specific Purposes, Vol. 12, 3-22.

Pilar Mur Dueñas, (2007). 'I/we focus ony': A cross-cultural analysis of self-mentions in business management research articles. Journal of English for Academic Purposes 6, 143-162.

Reed, Walter L., Marshall P. Duke, (2005). Personalities as Dramatis Personae, An Interdisciplinary Examination of the Self as Author. Common Knowledge 11:3, 502-513.

Roux Rodríguez, Ruth, Alberto Mora Vázquez, Nelly Paulina Trejo Guzmán (2011). Exploring Writer Identity in Mexican EFL Students' Academic Writing. Ikala, revista de lenguage y cultura Vol. 16, No. 28, $93-115$.

Swales, J.M. \& C.B. Feak (2004, 2nd edition). Academic Writing for Graduate Students: Essential Tasks and Skills. Ann Arbor: University of Michigan Press.

Swales, John M., (1990). Genre Analysis: English in Academic and Research Settings, Cambridge: Cambridge University Press.

Tang, Ramona, John Suganthi (1999). The 'I' in identity: Exploring writer identity in student academic writing through the first person pronoun. English for Specific Purposes 18, S24 - s39.

Tarone, Elaine, Sharon Dwyer, Susan Gillette, and Vincent Icke (1998). On the Use of the Passive and Active Voice in Astrophysics Journal Papers: With Extensions to other Languages and other Fields. English for Specific Purposes, Vol. 17, No. 1, 113 - 132.

Valero-Garces, Carmen (1996). Contrastive ESP Rhetoric: Metatext in Spanish-English Economics Texts. English for Specific Purposes, Vol. 15, No. 4, 279-294.

Van der Geer, J., Hanraads, J. A. J., \& Lupton, R. A. (2000). The art of writing a scientific article. Journal of Scientific Communications, 163, $51-59$.

Vassileva, Irena (1998). Who am I/who are we in academic writing? International Journal of Applied Linguistics vol. 8, no. 2, 163 - 190.

Van der Geer, J., Hanraads, J. A. J., \& Lupton, R. A. (2000). The art of writing a scientific article. Journal of Scientific Communications, 163, $51-59$. 


\section{Biodata}

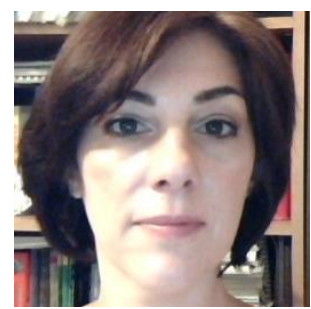

Teodora GHIVIRIGĂ is Assistant Professor at the Faculty of Letters within the Alexandru Ioan Cuza University of Iaşi, the Department of Modern Languages. She currently teaches Terminology, English Morphology, Semantics and translation. She has published articles on the terminology of Economics, the translation of texts on Economics, and on children's literature and also corpus based studies on research articles written by non-native (Romania authors) mainly in the field of Economics. She is also interested in English (British mainly) literature for children and in fantasy, especially in the works of the authors of the Inkling group. Didactic interests also include teaching English to adults (especially in specialized domains such as Business and Economics and Law) and testing.

Ghiviriga, T. (2015). Author Identity in Scientific Texts on Economics. Logos Universality Mentality Education Novelty, Section: Philosophy and Humanistic Sciences, III (1), 99-113 